\title{
LV Distribution Network Feeders in Belgium and Power Quality Issues due to Increasing PV Penetration Levels
}

\author{
Carlos Gonzalez, Jurgen Geuns, Sam Weckx, Graduate Student Member, IEEE, Thomas Wijnhoven, Graduate \\ Student Member, IEEE, Pieter Vingerhoets, Tom De Rybel, Johan Driesen, Senior Member, IEEE,
}

\begin{abstract}
In this paper, the impact of residential distributed energy resources (DER) on the power quality is investigated in four feeder types of the electrical LV distribution network in Flanders, Belgium. The investigated power quality issues are over-voltage, under-voltage and unbalance. The results of the simulations are discussed in detail. The paper leads to an estimation of the compliance to the power quality standard EN 50160 , and a summary of issues in the distribution grids when increasing the amount of DER.
\end{abstract}

Index Terms-Distributed Energy Resource, Power Quality, Under-voltage, Over-voltage, Unbalance.

\section{INTRODUCTION}

$\mathbf{T}$ HE countries in the European Union have defined different targets concerning the amount of renewable energy to be produced in the year 2020, taking the situation in 2005 as a reference point. This policy has resulted in a direct impact on the electrical distribution grids, which are experiencing significant changes due to integration of Distributed Energy Resources (DER), mainly photovoltaics, into low and mediumvoltage grids. The present paper is focused on the Flemish region of Belgium (its targets, in terms of share of energy from renewable sources in gross final consumption of energy, are shown in table I) [1].

TABLE I

TARGETS FOR BELGIUM

\begin{tabular}{c||r|r|r|r|r} 
Year & 2005 & 2012 & 2014 & 2016 & 2020 \\
\hline \hline Target (\%) & 2,20 & 5,44 & 7,06 & 9,22 & 13
\end{tabular}

As described in the literature [2], [3], many questions about PV installations behaviour arise when high penetration levels are achieved. Nowadays, the Flemish regulation, Synergrid C10/11, based partially on EN 50436 [4], states that for DER units below $5 \mathrm{kVA}$, the customers should only inform the Distribution System Operators (DSO's) that they have a DER unit connected to the LV distribution network. Furthermore, in Flanders, economic incentives for PV installations, in terms of guaranted minimum price have evolved during the lasts years. From January 2006, the guaranted minimum price for 20 years

C. Gonzalez, J. Geuns, S. Weckx, T. Wijnhoven, P. Vingerhoets, T. De Rybel and J. Driesen are with the Department of Electrical Engineering ESATELECTA, KULeuven, Kasteelpark Arenberg 10, bus 2445, 3001 Leuven, Belgium. Main author's email address: carlos.gonzalezdemiguel@esat.kuleuven.be was set at 0,45 Eur/kWh, in 2010, 0,35 Eur/kWh and in 2011, at $0,33 \mathrm{Eur} / \mathrm{kWh}[5]$.

Most of these DER units are photovoltaic installations placed either on the roof or in the garden of households. Nowadays, the number of DER units in the low-voltage network (penetration level) is not high in terms of houses with a connected PV unit. However, due to the economic incentives and subsidies to the new connections, the Flemish DSO's expect a large increase of photovoltaic installations in their grids.

However, large photovoltaic integration implies technical issues that must be investigated [6], [7], [8]. The main and immediate concerns of the DSO's, originating from the increased number of installations, are the compliance of the power quality standard EN-50160 in what concerns overvoltage, under-voltage and unbalanced situations. This paper investigates the impact of large-scale implementation of residential PV installations on the power quality of electricity supplied to the residential customers.

Besides compliance with the international standard, the Synergrid C10/11 Flemish norm limited the maximum voltage of the inverters to $106 \%$ of the nominal voltage, a limit much stricter than the $110 \%$ imposed by the power quality standard EN 50160 "Voltage characteristics of electricity supplied by public electricity networks" [9]. In practical terms, this implies that the inverters disconnect too soon, although complying with the power quality standard. Several customers expressed their complaints about this situation, which has a considerable negative economic impact. Recently, allowed by Synergrid, the inverters tripping value increased from $106 \%$ to $110 \%$ effectively allowing the inverters to work within a wider voltage range.

\section{Power QUALITY PARAMETERS}

The standard EN-50160 [10], "Voltage Characteristics of electricity supplied by public distribution systems" is applied to regulate the power quality in Flanders [11]. It classifies the different voltage phenomena that can take place in the grid (under-voltage, over-voltage, unbalance, flicker, dips, swells, etc), the parameters to quantify these phenomena and the admissible limits for these parameters. Within this paper, only over-voltage, under-voltage and unbalance situations have been studied, as these are of primary concern to the DSO.

In case of residential grids, single and three-phase domestic appliances are used by the households. These appliances are 
designed for a wide range of voltages to ensure correct operation. However, if under-voltage or over-voltage situations occur (exceeding the limits), their functionality is no longer guaranted and might even be damaged. In comparison to voltage magnitudes issues, unbalanced conditions may affect three-phase equipment.

\section{A. Over and under-voltage}

The nominal voltage line-to-neutral voltage is $230 \mathrm{~V}$ (Un), as defined by [10]. During the normal operation, the 10 minutes mean r.m.s. voltage shall be within the range Un \pm $10 \%(253 \mathrm{~V} ; 207 \mathrm{~V})$, during $95 \%$ of the time, evaluated during the period of one week. Furthermore, all the 10 minutes mean r.m.s. voltages shall be within the range of Un $+10 \%$ and Un - $15 \%(253 \mathrm{~V} ; 195,5 \mathrm{~V})$.

\section{B. Unbalance}

The positive and the negative voltage sequences are obtained through the Fortescue transformation [12] of the 3-phase voltages at a certain node in the distribution network. The unbalance factor (VUF) is defined in equation 1 :

$$
V U F=100 \% \times \frac{\left|V_{\text {negative sequence }}\right|}{\left|V_{\text {positive sequence }}\right|}
$$

The measured VUF in any node must stay below $2 \%$ for the $95 \%$ of the time, evaluated over one week.

In table II, the accompanying criteria for each parameter are summarized.

TABLE II

INVESTIGATED POWER QUALITY PARAMETERS

\begin{tabular}{lrrr} 
Power quality parameter & Min & Max & Compliance \\
\hline \hline Voltage magnitude & $-10 \%$ Un & $+10 \%$ Un & $95 \%$ week \\
& $-15 \%$ Un & $+10 \%$ Un & $100 \%$ week \\
\hline Unbalance (VUF) & - & $2 \%$ & $95 \%$ week
\end{tabular}

\section{FEEDER SELECTION}

The grid in Flanders is studied through four distribution networks that are, according to the DSO's Eandis [13] and Infrax [14] assumed to be representative for the Flanders AC LV distribution network. The LV distribution network is considered to begin at the MV side of the MV/LV distribution transformer and several feeders start from the LV busbar. Therefore, the voltage at the busbar is function of the voltage drop over the MV/LV transformer, caused by the power flows on all the connected distribution feeders. By considering the feeders separately and fixing the LV busbar voltage this dependency is ruled out.

The feeders of each distribution networks are classified in different classes [15], to sort them by these classes and select the feeder that represents a certain class best, with the most households connected to it. The selected feeders will be used in the simulations.

\section{A. Feeder classification}

The LV feeders of the studied distribution networks are classified according to the average length between two consecutive households and the house construction type. These criteria divide the feeders in 4 categories: city, urban, semiurban and rural feeders.

1) Average length between two consecutive households: It is calculated using Formula 2:

$$
A V G L=\frac{\sum_{n=1}^{m} l_{n}}{L P}
$$

Where:

- $A V G L$ is the average length between the two consecutive households

- $l_{n}$ is the length of feeder part $\mathrm{n}$

- $L P$ is the total number of load points connected to the feeder

- $m$ is the total number of feeder parts

2) Construction type: Houses (single unit and multi-unit houses) in Flanders are "attached", "detached" and "semiattached". The term "attached" refers to closed houses, with two houses, one at each side; "semi-detached" corresponds to, for instance, corner houses, attached to only one house, and "detached" refers to completely open houses, typical in rural areas. A single-unit house corresponds to a single-family building with only one tenant, whereas a multi-unit house refers, for instance, to an appartment building, with several tenants.

The parameters used for the classification are summarized in Table III.

TABLE III

\begin{tabular}{|c|c|c|c|c|c|}
\hline Parameter & Type 1 & Type 2 & Type 3 & Type 4 & Units \\
\hline AVGL & $\leq 10$ & $\begin{array}{l}10 \leq x \\
x \leq 20\end{array}$ & $\begin{array}{l}20 \leq x \\
x \leq 40\end{array}$ & $\geq 40$ & {$[\mathrm{~m}]$} \\
\hline Attached & $\leq 75$ & $\geq 50$ & $\leq 30$ & $\leq 10$ & $\%$ \\
\hline Semi-detached & $\leq 25$ & $\geq 25$ & $\geq 30$ & $\leq 15$ & $\%$ \\
\hline Detached & 0 & $\leq 15$ & $\leq 50$ & $\geq 50$ & $\%$ \\
\hline
\end{tabular}

PARAMETERS FOR THE FEEDER CLASSIFICATION

\section{B. Feeder selection}

The total population of 29 feeders is divided into subpopulations according to the feeder category i.e. city, urban, semiurban and rural. From the classified feeders, a representative one for each class is selected. The selected feeders, shown in Table IV, are the feeders from the sub-populations, that best fit the feeder profiles.

\section{SCENARIOS}

In order to cope with the numerous situations that the contemporary grid can experience in the short or the long term, several scenarios have been designed to be simulated. They combine the multiple inputs involved within the project: feeder topologies, load and generation profiles, PV penetration level (in percentage of houses in the feeder), PV-size statistics and the PV location. The variable space is shown in Table V. 
TABLE IV

THE SELECTED FEEDERS AND THEIR ACCOMPANYING PARAMETERS

\begin{tabular}{lrrrr} 
Feeder class & City & Urban & Semi-Urban & Rural \\
\hline \hline Total length of the feeder (m) & 417 & 509 & 1657 & 874 \\
Number of load points (Households) & 52 & 42 & 63 & 20 \\
Number of load points (Apartments) & 3 & 0 & 0 & 0 \\
Number of generation points & 0 & 2 & 0 & 3 \\
AVGL (m) & 7,6 & 12,1 & 26,3 & 43,7 \\
Attached single-unit house (\%) & 85 & 75 & 0 & 0 \\
Semi-detached single-unit house (\%) & 5 & 25 & 25 & 0 \\
Detached single-unit house (\%) & 5 & 0 & 75 & 100 \\
Attached multi-unit house (\%) & 5 & 0 & 0 & 0 \\
Semi-detached multi-unit house (\%) & 0 & 0 & 0 & 0 \\
Detached multi-unit house (\%) & 0 & 0 & 0 & 0 \\
Feeder parts & 3 & 3 & 7 & 3
\end{tabular}

TABLE V

VARIABLE SPACE OF THE VARIABLES USED IN THE SIMULATIONS

\begin{tabular}{llr} 
Variable & Variable space & Units \\
\hline \hline PV Penetration & {$[5 ; 12,5 ; 25 ; 50 ; 100]$} & {$[\%]$} \\
PV Location & {$[$ Beginning; End; Random; 1Phase] } & \\
Load factor & {$[96 ; 100 ; 103,78]$} & {$[\%]$} \\
Base voltage & {$[207 ; 230 ; 253]$} & {$[V]$}
\end{tabular}

The combination of these variables leads to 180 scenarios per feeder. All these scenarios were simulated and the results analyzed. In the next subsections, the inputs to build the scenarios are presented.

\section{A. Load profiles}

The selected feeders need to be populated with customers and houses, represented by their power consumption. Eandis and Infrax have provided 100 yearly load profiles, 15 minutes based, that provide the active power consumption (kW). The considered load profiles through this study are single-phase, thus those ones that exceed the maximum current of $63 \mathrm{~A}$ are rejected (maximum allowed per single-phase household) [9]. The remaining load profiles can be freely distributed along the feeders.

1) Load factor: The scope of the Linear project foresees the evolution of the residential load from 2010 to 2020 . The load forecasts done within the project for the year 2020 indicate that from the actual load situation two possibilities can happen: either the load base increases up to $103,78 \%$ or it decreases till $96 \%$ [16]. The set of simulations includes the actual load base about $100 \%$. In terms of implementation, the load profiles are multiplied by the load factor.

\section{B. Generation profiles}

Within the scope of this paper, only single-phase photovoltaic $(\mathrm{PV})$ installations are considered in this paper, connected to the same phase as the load. According to the Flemish standard $\mathrm{C} 10 / 11$, it is not allowed to deliver reactive power [9]. Therefore, the power factor of the PV installations is set to 1 . As in the case of load profiles, also a generation profile is required to complete the household profile if a PV unit is connected.
1) PV size: Moreover, the DSO's provided statistics concerning the distribution curve about the peak-power size of the PV installations in Flanders (Fig. 1).

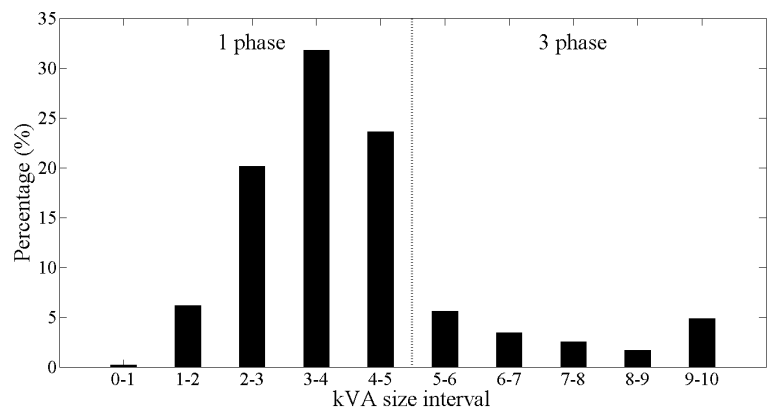

Fig. 1. PV-size distribution curve in 2010

In LV networks and for single-phase connections, the maximum installed peak-power allowed is $5 \mathrm{kVA}$, whereas for three-phase connections, the maximum rises up to $10 \mathrm{kVA}$. Since in this study only single-phase houses are considered, the statistics are cut after $5 \mathrm{kVA}$. The size of the PV installation of each house has been decided: first, according to the statistics of Fig. 1, and second, by proportional criteria: the higher the yearly consumption of the house, the higher the size of the PV unit.

The region or area covered by one feeder is relatively small (few hectares), thus it can be assumed that all the PV units connected to this feeders will receive approximately the same solar irradiation, so the same generation profile can be applied for all the PV installations. In practical terms, the orientation of the roofs (and the panels), some shadowing phenomena (buildings, trees and so on), and many other factors imply that every single PV installation generates a different profile. It would imply less PV generation, since the shadows would limit the output power of the PV panels, and furthermore, the impact of the PV units over the grid would be less significant.

\section{DER penetration level}

The penetration level of the distributed energy resources is expressed as the percentage of houses with DER units over the total amount of houses in the feeder. To deal with the actual situation, 2010, a penetration level about $5 \%$ of the houses has been considered, according to the statistics in Fig. 2 .

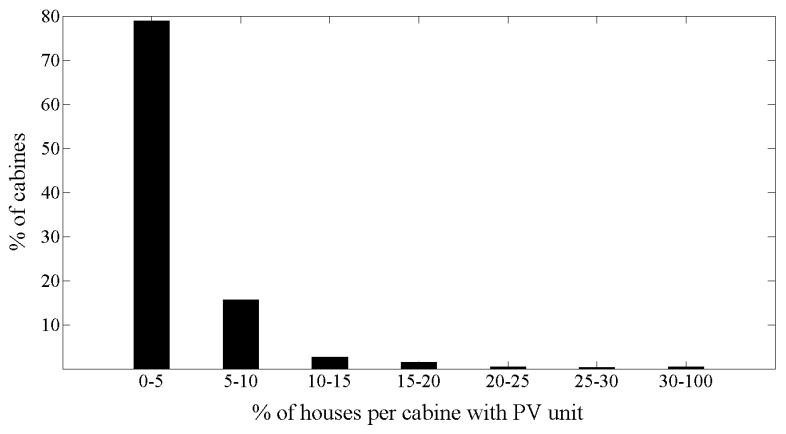

Fig. 2. PV penetration level in 2010 


\section{DER location}

In order to study the extreme cases, the DER units have been located in differents places of the grid: at the beginning (close to the distribution transformer), at the end (far away from the transformer) and randomly among the feeder.

As well, the situation when all the PV installations are connected to the same phase has been considered (all PV units in phase $\mathrm{A}$, for instance). In this case, since only one third of the houses is connected to phase $\mathrm{A}$, the maximum PV penetration level is also one third: restricted to the houses connected to phase A. As it can be expected, this PV location, in combination with an increasing penetration level, leads to unbalanced voltages and power quality problems (see section $\mathrm{V}-\mathrm{C})$.

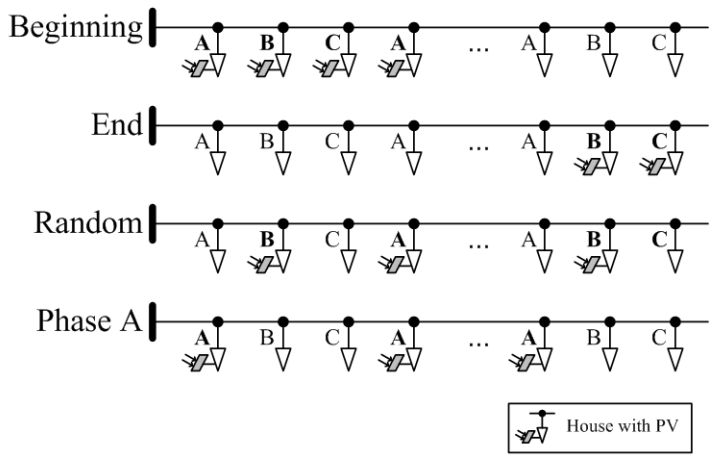

Fig. 3. PV locations

\section{E. Base voltage}

Although the voltage drop or rise over transformer is not included in this paper, a change in the base voltage of the busbars (start of distribution feeder) is included in the simulations. The voltage fluctuations that can be produced in the medium voltage side of the transformer may have a direct impact over the results. Three voltage levels at the beginning are considered, the nominal one, $230 \mathrm{~V}, 207 \mathrm{~V}$ (90\% Un), and the highest one, $253 \mathrm{~V}$ (110\% Un).

It has to be taken into account that the distribution transformers are equipped with tap changers to be used for voltage regulation purposes [17]. In practical operation, these tap changers are usually off-load types and barely used.

\section{F. Grid models}

Each feeder model was developed with Neplan V545, Research Version.

- The loads have been considered as single phase PQ-loads, although only the active power is defined by the load and generation profiles.

- The loads are assigned to different phases following the sequence $\{1,2,3,1,2,3, \ldots\}$.

- The cables have been modelled by the their positive and homopolar impedances, at a nominal temperature of 25 degrees and an operational temperature of 45 degrees. All of the cables are considered as underground [11].

- The method used to carry out the asymmetrical load flow is the "Backward-forward sweep" [18].

\section{Simulations}

In section IV-A, the fact has been introduced that, given a load profile (customer), it is assigned to a certain load (node). The arising questions are "which load profile?" and "to which node?". If the most consuming load profiles (or the least) are placed on the same phase, the simulations will lead to exaggerated and unbalanced results. Nevertheless, a certain degree of unbalance should be expected in residential grids, due to the unpredictable nature of the loads.

It is necessary to distribute the load profiles in the grid in a specific way, and also to know the influence of the load profile distribution over the results.

\section{A. Sensitivity analysis}

A sensitivity analysis has been carried out on the urban feeder (42 households). Three scenarios have been considered:

1) The most consuming load profiles are randomly assigned to phase A. The less consuming profiles are randomly assigned to phases $\mathrm{B}$ and $\mathrm{C}$.

2) A load profile assignment that gives a similar results to the average of the ones obtained by 100 different combinations.

3) The less consuming load profiles are randomly assigned to phase $\mathrm{A}$. The most consuming profiles are randomly assigned to phases $\mathrm{B}$ and $\mathrm{C}$.

The results show that the maximum voltage difference between case 1 (or case 3 ) and case 2 , is about $3 \mathrm{~V}$, and in terms of VUF, the maximum difference is $0.17 \%$. In addition, the average load profile assignment was selected to populate the grids in the final simulation set.

The results obtained from the simulations were complementary to those found in [19], where a sensitivity analysis on the voltage unbalance parameter was performed by varying the cable types, their length, or PV configurations.

\section{B. Simulation outputs}

The study has provided five main outputs of interest:

1) The compliance with the power quality standard in what concerns voltage magnitude and unbalance. Since the time compliance is defined as weekly, the number of weeks per year with power quality problems is given.

2) Over-voltage indicator: 100th voltage percentile (maximum voltage, during $100 \%$ of the time), which can be understood as the distance to the over-voltage limit (110\% Un).

3) Under-voltage indicator (1): 5th voltage percentile, which represents the distance to the first under-voltage limit (90\% Un) during $95 \%$ of the time.

4) Under-voltage indicator (2): Oth voltage percentile (minimum voltage, during $100 \%$ of the time), which can be understood as the distance to the lower-voltage limit (85\% Un).

5) Voltage Unbalance Factor 95th percentile, which represents the distance to the standard limit during $95 \%$ of the time. 


\section{Results}

The results obtained from the simulations are of interest when understanding the consequences of increasing PV penetration. On one side, the compliance with the standard can help the DSO's to foresee the behaviour of their grids and on the other side, the percentiles provide a numerical estimation about the voltages during a certain percentage of time.

1) Compliance: The compliance with the power quality standard depends on many factors. At the base voltage of 230 $\mathrm{V}$, only the semi-urban and the city feeders might incur power quality problems, depending on the penetration level, the PV location and the load level. Table VI summarizes the issues found.

TABLE VI

SUMMARY OF POWER QUALITY COMPLIANCE

\begin{tabular}{lllll} 
Feeder & Problem & Location & PV level & Load \\
\hline \hline \multirow{2}{*}{ Semi-urban } & Over-voltage & Phase A & $\geq 50 \%$ & All \\
& Unbalance & Phase A & $100 \%$ & All \\
\hline City & Over-voltage & Phase A & $\geq 50 \%$ & All \\
& & All & $100 \%$ & All \\
& Under-voltage & All & $\leq 50 \%$ & $\geq 100 \%$ \\
& Unbalance & Phase A & $100 \%$ & All
\end{tabular}

Table VI shows under which conditions power quality problems may occur. The location of the PV units, in combination with the PV penetration level and the load level may create problems.

2) Percentiles: The extreme percentile values are plotted in Fig. 4, where the limits for $100 \%$ of the time are shown. The upper limit is $253 \mathrm{~V}$ and the lower minimum voltage $(195,5$ $\mathrm{V}$ ). The lower limit of $207 \mathrm{~V}$ (for $95 \%$ of the time) is not shown in the plot, but none of the feeders falls below this value, for the 5th voltage percentile.

As it can be observed in Fig. 4, one of the trends is an increase of the maximum 100th voltage percentiles, especially when the PV units are located at phase A. In the semi-urban and the city feeder, for high penetration levels, the over-voltage limit is even exceeded, according to the information shown in Table VI.

Another trend is that the minimum 5th and 0th percentiles decrease when the penetration level increases (semi-urban and urban feeder). However, in the city feeder, the minimum 0th percentile increases, whereas the 5 th percentile decreases. This trend occurs because the PV units are able, here, to compensate partially the load peaks, but also because of the neutral point shift. These phenomena under these results will be further detailed in section V-D.

Fig. 5 shows the maximum 95th VUF percentiles and the limit (2\%) imposed by the power quality standard.

\section{Analysis and phenomena}

The most extreme situations, regarding the compliance with the power quality standard, have been found when the PV units were connected to phase A. This PV location leads either to over-voltage or under-voltage. Low load level scenarios have been identified as prone to over-voltage situations, whereas the scenarios with high load level scenarios are favourable to
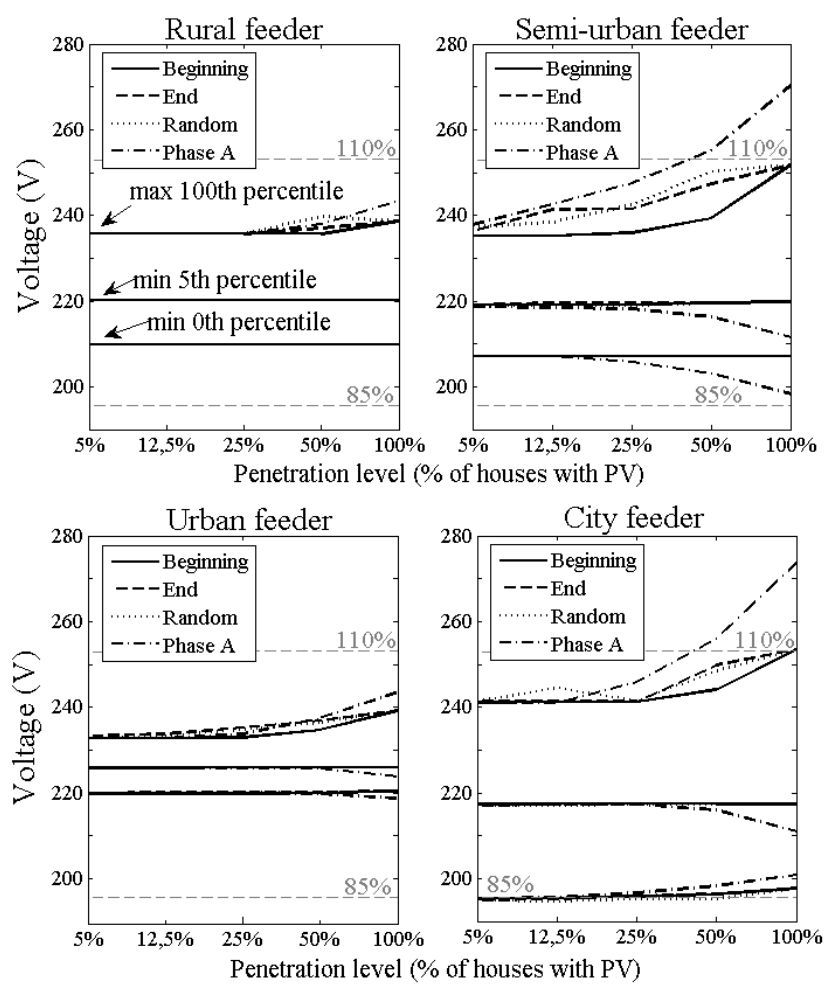

Fig. 4. Voltage percentiles
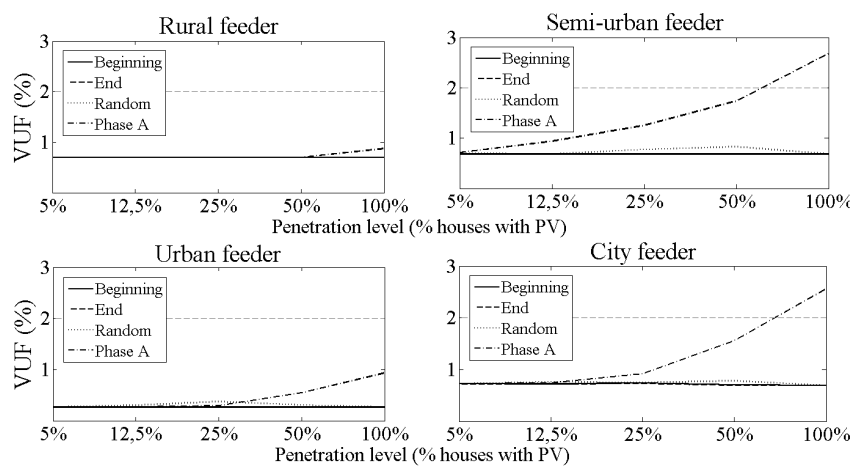

Fig. 5. VUF 95th percentiles

under-voltage and unbalance. For low PV penetration levels, as nowadays, the realistic scenarios are those at a $100 \%$ of load level and the PV units connected randomly along the feeder.

The evolution of the output parameters (described in section V-B) in specific cases reveal the existence of phenomena and issues that take place in the grid.

1) General unbalance in the network: The number of loads connected to each phase is approximately the same in all the feeders and the phase of each customer can be known. However, the consumption of each household cannot be controlled, only measured. This leads to a small general unbalance in the network. The voltage in the most loaded phases, in average, will be lower than in the less loaded phases, leading to the mentioned unbalance.

2) Limited load compensation: This phenomena refers to the ability of the PV units to reduce (compensate) the amount of load demanded by the household. The PV installation pro- 
duces a part of the power that the consumer would otherwise take from the grid. However, this compensation is limitted due to several factors, such as the natural fluctuations of the PV generation like day-night, sunny-cloudy, summer-winter, the variability of the consuming patterns, and so on.

The evening load peaks, for instance, will not be compensated by connecting a PV unit, as it can be observed in Fig. 6, where a load profile and the PV generation are plotted during 7 days.
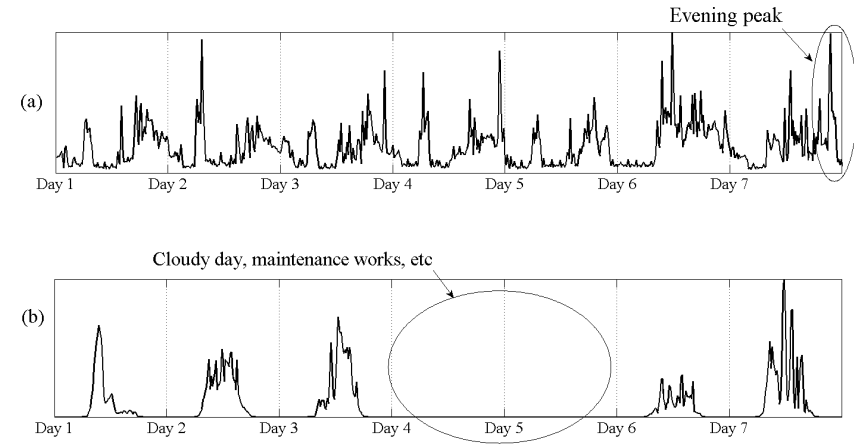

Fig. 6. Profiles. (a) Load profile; (b) PV generation profile

As a consequence, the minimum voltages, produced by evening load peaks will remain constant while the PV penetration level increases. This phenomenon can be observed in the rural feeder, when analising the absolute minimum voltage (the three phases) at one of the last nodes, when increasing the PV penetration level (Fig. 7).

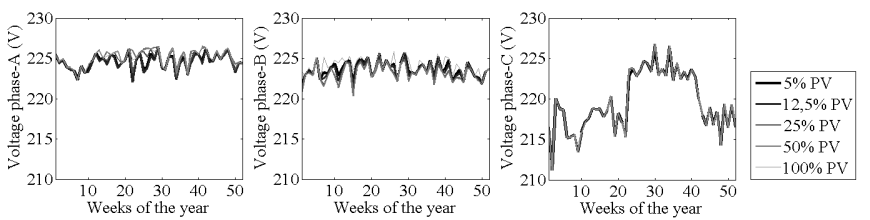

Fig. 7. Absolute minimum voltage at one of the last nodes of the rural feeder

3) Different raise of $P V$ units in the phases: This phenomena can be found only when the PV units are connected randomly along the feeder. The underlying issue is that the connection of PV installations is not coordinated, in terms of a similar number of PV units in each phase. An uncoordianted connection can lead to the case of all PV units generating on only one phase. It has been shown in table VI, that the most problematic scenarios are found under these conditions, when all the PV's are connected to phase A.

The case of all PV units connected to phase A, leads to over-voltage situations (observed only in the semi-urban and the city feeders). Fig. 8 shows the evolution of the maximum voltage when increasing the penetration level. The voltage is plotted for the three phases of one of the last node of the sermi-urban feeder, where the over-voltage problems can be observed (above $253 \mathrm{~V}$ ) for the scenario prone to over-voltage.

The Voltage Unbalance Factor is also affected by this uncoordinated connection, till reaching high values that exceed the limit defined by the power quality standard. In Fig. 9, the
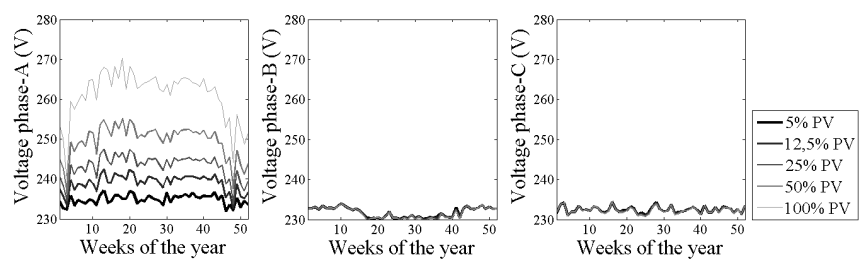

Fig. 8. Absolute maximum voltage at one of the last nodes of the semi-urban feeder

unbalance in the same node as before evolution is plotted, in the scenarios most sensitive to unbalance.

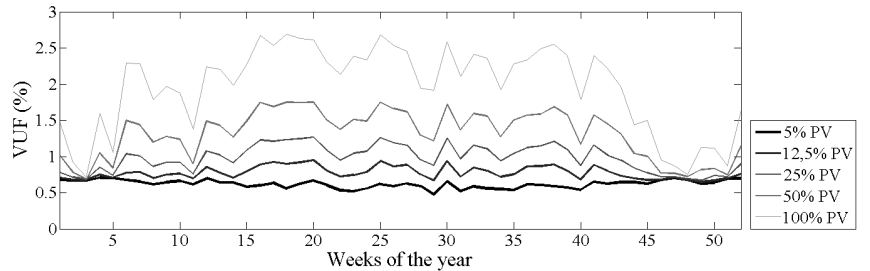

Fig. 9. 95th VUFe percentile at one of the last nodes of the semi-urban feeder, PV's in phase A

Furthermore, since the connection of PV units is not only limited to phase A, the other phases can admit as well PV installations, solving partially the rising Voltage Unbalance Factor. As a result, it can be observed that the unbalance fluctuates while increasing the PV penetration level, till reaching unbalance levels similar to the original ones, or even below. This case is shown in Fig. 10. Herein, the VUF in one of the last nodes of the feeders is plotted for the realistic scenarios (PV units randomly connected along the feeder).

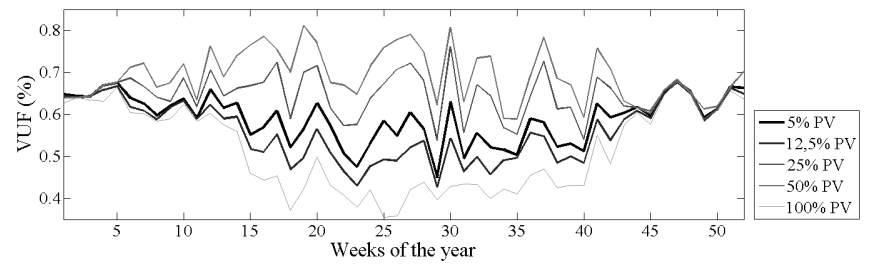

Fig. 10. 95th VUFe percentile at one of the last nodes of the semi-urban feeder, PV's randomly connected

4) Neutral point shifting: The uncoordinated connection of the PV units has also another side effect, which has been described in literature as "neutral point shifting" [20] [21]. It refers to the migration of the neutral point in presence of unbalanced three-phase and single-phase loads due to the resistive and inductive voltage drop across the neutral conductor (Fig. 11).

From the simulations results, this effect can be found in the city feeder, when analizing the lowest voltages at the end of the feeder, in Fig. 12. Herein, the scenarios prone to over-voltage situations are plotted.

In Fig. 12, the minimum voltage in phase $\mathrm{A}$ is almost not changed, whereas phase $\mathrm{B}$ changes significantly and $\mathrm{C}$ decreases slightly. As it can be understood from the Fig. 11, this phenomena affects to both phases, but mainly to the next phase where the PV units are connected. 


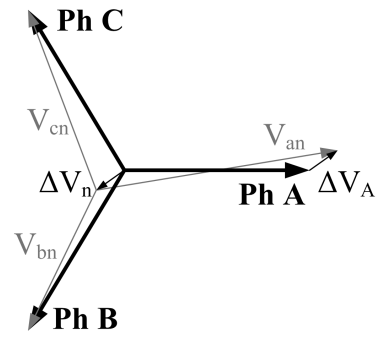

Fig. 11. Neutral displacement due to PV injection

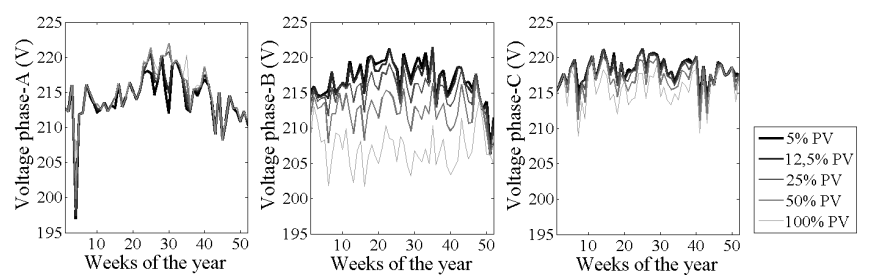

Fig. 12. Absolute minimum voltages at one of the last nodes of the city feeder, PV's in phase A

\section{Conclusions}

The population of feeders from the representative distribution networks is limited to 29 feeders. Therefore, it can be questioned whether these cases can represent the whole $\mathrm{AC}$ LV distribution network in Flanders. No studies have been performed to evaluate whether these feeders are representative for the whole LV grid. In consequence, these results cannot be generalized, but give a good approximation of the phenomena that are expected to happen in feeders with similar topology.

The compliance with the power quality standard may not be always achieved, concerning the studied parameters. Some feeders, like the rural or the urban, may be able to handle massive PV connection without incurring power quality problems. The semi-urban and the city feeders may experience problems, over-voltage and unbalance, at very high PV penetration levels. The city feeder may experience also problems of under-voltage at low penetration levels.

The impact of the increasing PV penetration level can be seen under different perspectives. For the city feeder, which may incur under-voltage, an increasing number of distributed generation (till very high PV penetration levels) helps to remove these problems, wherever the PV units are connected. As a negative effect, the massive PV connection may lead to voltage and unbalance peaks, especially when all PV units are connected to the same phase.

Concerning the analysis of the results, several phenomena have been found to take place in the distribution grids:

- The load distribution introduces a general unbalance in the grid.

- Single-phase loads introduce local unbalance.

- The neutral point shifting effect may occur, and may be significant, at very high penetration levels and at very unbalanced situations.

- PV natural fluctuations limit the load compensation.

- The increasing penetration level may introduce and remove the unbalance.
The topology of the low-voltage feeders is often planned based on economic models of the grid elements and the available paths to reach the customers. In consequence, the distribution network design becomes an optimization problem: to minimize the cost, to reach all the customers and so on. Some authors include the constraint of minimum voltage to ensure that the solution will not incur under-voltage. However, neither the load level nor the PV penetration level remain constant in time. A clear example is the penetration of the electric vehicle, which implies a non negligible load increase. Since a distribution substation includes several feeders, with different topologies and lengths, it seems necessary to consider carefully the critical feeders, those that may incur power quality problems.

The simulations ran at different voltage levels at the transformer indicate that the occurrence of power quality problems, such as over or under-voltage, depends directly on the voltage regulation capacity. The voltage level can be imposed either at the low-voltage or the medium-voltage busbar of the transformer. The influence of the medium-voltage side may be a factor to consider when dealing with full grids, with transformer and several feeders.

Future research will aim to find technical solutions that may be suitable to fix the issues identified and to find out the real influence of the neutral point shifting on the distribution grids. Moreover, the results herein obtained, within the Linear project, are planned to be practically demonstrated in a field test in one of the simulated grids. In consequence, the household consumption profiles and the voltages will be available to verify the models and the obtained results.

\section{ACKNOWLEDGMENT}

The work is supported via the project Linear organised by the Institute for Science and Technology (IWT). S. Weckx and T. Wijnhoven have a PhD fellowship of the Research Foundation - Flanders (FWO).

\section{REFERENCES}

[1] "Directive 2009/28/EC of the European Parliament and of the Council of 23 April 2009, on the promotion of the use of energy from renewable sources and amending and subsequently repealing Directives 2001/77/EC and 2003/30/EC," Official Journal of the European Union, 2009.

[2] "DISPOWER: Distributed Generation with High Penetration of Renewable Energy Sources (Final Public Report)," ISET - Institut fur Solare Energiewersorgungstechnik e. V. (Coordinator), Final Report, 2006.

[3] "SOLID-DER: Co-ordination action to consolidate RTD activities for large-scale integration of DER into the european electricity market. D2.3: Technical \& System Constraints for DER integration," Fundacion LABEIN, Final Report, 2008.

[4] "EN 50436. Requirements for the Connection of Microgenerators in Parallel with Public Low-voltage Distribution Networks," CENELEC Std., December 2007.

[5] "PV Status Report 2011 (EUR 24807 EN 2011)," European Commission Joint Research Centre Institute for Energy, Via Enrico Fermi 2749 21027 Ispra (VA) Italy, Tech. Rep., 2011. [Online]. Available: http://ie.jrc.ec.europa.eu

[6] T. V. Van, A. Woyte, and F. H. et al., "The Meta PV Project: Photovoltaics for Active Distribution Systems," in 24th European Photovoltaic Solar Energy Conference, Hamburg, Germany, September 2009. 
[7] M. Braun, T. Stetz, and R. B. et al., "Is the distribution grid ready to accept large-scale photovoltaic deployment? state of the art, progress, and future prospects," Progress in Photovoltaics: Research and Applications, 2011.

[8] E. Demirok, D. Sera, R. Teodorescu, P. Rodriguez, and U. Borup, "Clustered PV inverters in LV networks: An overview of impacts and comparison of voltage control strategies," in Proc. IEEE Electrical Power \& Energy Conf. (EPEC), 2009, pp. 1-6.

[9] "Specifieke technische voorschriften voor decentrale productieinstallaties die in parallel werken met het distributienet (C10/11)," 2009.

[10] "NEN-EN 50160 Voltage characteristics of electricity supplied by public electricity networks", Std., 2010.

[11] "Rapport van de vlaamse regulator van de elektriciteits- en gasmarkt mat betrekking tot de kwaliteit van de dienstverlening van de elektriciteitsdistributienetbeheerders in het vlaamse gewest in 2010," Vlaamse Regulator van de Elektriciteits- en Gasmarkt (VREG), Tech. Rep., 2011.

[12] C. L. Fortescue, "Method of symmetrical co-ordinates applied to the solution of polyphase networks," Transactions of the American Institute of Electrical Engineers, no. 2, pp. 1027-1140, 1918.

[13] "Van productie tot stopcontact - De levering van elektriciteit in Vlaanderen," 2010. [Online]. Available: http://www.eandis.be/eandis/

[14] Infrax. [Online]. Available: http://www.infrax.be/nl

[15] A. Bertani, C. Bossi, and B. D. et al, "Electrical energy distribution networks: actual situation and perspectives for distributed generation," in 17th International Conference on Electricy Distribution. CIRED, 2003.

[16] "Energie- en broeikasgasscenarios voor het vlaams gewest," Vlaamse Instituut voor Technologisch Onderzoek (VITO), Tech. Rep., April 2007.

[17] J.-H. Choi and J.-C. Kim, "Advanced voltage regulation method of power distribution systems interconnected with dispersed storage and generation systems," vol. 16, no. 2, pp. 329-334, 2001.

[18] C. Cheng and D. Shirmohammadi, "A three-phase power flow method for real-time distribution system analysis," Power Systems, IEEE Transactions on, vol. 10, no. 2, pp. $671-679$, may 1995.

[19] F. Shahnia, R. Majumder, A. Ghosh, G. Ledwich, and F. Zare, "Sensitivity analysis of voltage imbalance in distribution networks with rooftop PVs," in Proc. IEEE Power and Energy Society General Meeting, 2010, pp. 1-8.

[20] L. Degroote, B. Renders, B. Meersman, and L. Vandevelde, "Neutralpoint shifting and voltage unbalance due to single-phase DG units in Low Voltage distribution networks," in Proc. IEEE Bucharest PowerTech, 2009, pp. 1-8.

[21] R. D'hulst and E. Peeters, "Distributed voltage control strategies in a LV distribution network," in International Conference on Renewable Energies and Power Quality (ICREPQ10), Granada (Spain), 23rd to 25th March, 2010, 2010.

\section{BIOGRAPHIES}

Carlos Gonzalez received his M. Sc in Electrotechnics in Polytechnic University of Catalonia (UPC, Barcelona Tech) in 2009. From 2006 till 2010, he was researcher in Citcea - UPC and IREC, Barcelona, Spain. Since 2010, he is Ph.D. student and research assistant in ESATELECTA in the Katholieke Universiteit Leuven (KULeuven), Belgium. His research interests include power quality in smart grids and fault detection.

Jurgen Geuns received his Master degree in Industrial Engineering in 2006 and his M.Sc. degree in Electromechanical Engineering in 2010 from respectively the Katholieke Hogeschool Kempen (KHK) and the Katholieke Universiteit Leuven (KU Leuven). From 2010 till 2011, he was working as a researcher at the electrical engineering department ESAT-ELECTA at the Katholieke Universiteit Leuven (KULeuven), Belgium. His research was focused on electrical MV-LV AC/DC Distribution Networks.

Sam Weckx (S'11) received the M.Sc. degree in Electrical Engineering in 2009 and Mechanical Engineering in 2010 from the Katholieke Universiteit Leuven (KU Leuven), Belgium, where he is currently working towards the $\mathrm{Ph}$.D. degree as a research assistant with the division ESAT-ELECTA. His research interests include the application of distributed optimization in smart grids and voltage control in distribution networks.

Thomas Wijnhoven received the M.Sc. degree in Electrical Engineering, from the KU Leuven, Belgium, in 2008 (with highest honor). After working in industry at the electrical power supply department of BASF Antwerp, Belgium, he returned to the KU Leuven in 2011 where he is currently working towards the Ph.D. degree. In 2011 he also received a Ph. D. fellowship of the Research Foundation - Flanders (FWO). His research interests include power system protection, power system simulation, distributed generation and inverter control.

Pieter Vingerhoets is postdoctoral researcher at the Department of Electrical Engineering (ESAT) of the KU Leuven. He performs research and project cordination on monitoring and control in smart grids. He is co-author of 15 journal and conference articles. He received his M.Sc. in physics and his $\mathrm{PhD}$ in nuclear physics from the KU Leuven, Belgium in 2006 and 2011 respectively.

Tom De Rybel received the Industral Engineer degree in electronics design from Hogeschool Gent, Belgium, in 2002 and the M.A.Sc and PhD degrees in power systems from the University of British Columbia, Vancouver, Canada, in 2005 and 2010, respectively. His research interests, as a post-doctoral fellow at KU Leuven, Belgium, include smart-grid component design, high-voltage instrumentation, asset condition monitoring, power electronics, numerical acoustics, and hardware-in-the-loop simulation.

Johan Driesen (S93 - M97 SM12) received the M.Sc. and Ph.D. degrees in Electrical Engineering from the Katholieke Universiteit Leuven (KU Leuven), Leuven, Belgium, in 1996 and 2000, respectively. Currently, he is a Professor with the KU Leuven and teaches power electronics and electric drives. In 2000, he was with the Imperial College of Science, Technology and Medicine, London, U.K. In 2002, he was with the University of California, Berkeley. Currently, he conducts research on distributed generation, power electronics, and its applications. 